\title{
Th17 cells confer long-term adaptive immunity to oral mucosal Candida albicans infections
}

\author{
N Hernández-Santos ${ }^{1}$, AR Huppler ${ }^{1}$, AC Peterson ${ }^{1}$, SA Khader ${ }^{2}$, KC McKenna ${ }^{3}$ and SL Gaffen ${ }^{1}$
}

Oropharyngeal candidiasis (OPC) is an opportunistic infection caused by Candida albicans. Despite its prevalence, little is known about $C$. albicans-specific immunity in the oral mucosa. Vaccines against Candida generate both Thelper type 1 (Th1) and Th17 responses, and considerable evidence implicates interleukin (IL)-17 in immunity to OPC. However, IL-17 is also produced by innate immune cells that are remarkably similar to Th17 cells, expressing the same markers and localizing to similar mucosal sites. To date, the relative contribution(s) of Th1, Th17, and innate IL-17-producing cells in OPC have not been clearly defined. Here, we sought to determine the nature and function of adaptive T-cell responses to OPC, using a new recall infection model. Mice subjected to infection and re-challenge with Candida mounted a robust and stable antigen-specific IL-17 response in CD4 + but not CD8 + Tcells. There was little evidence for Th1 or Th1/Th17 responses. The Th17 response promoted accelerated fungal clearance, and Th17 cells could confer protection in Rag1 - / - mice upon adoptive transfer. Surprisingly, CD4 deficiency did not cause OPC but was instead associated with compensatory IL-17 production by Tc17 and CD3 + CD4 - CD8 - cells. Therefore, classic CD4 + Th17 cells protect from OPC but can be compensated by other IL-17-producing cells in CD4-deficient hosts.

\section{INTRODUCTION}

Candida albicans is a dimorphic fungus frequently found in the oral cavity that is nonpathogenic in healthy individuals. Immunocompromised patients frequently suffer from oropharyngeal candidiasis (OPC, "thrush"), characterized by painful pseudomembranous lesions in the tongue, pharynx, and buccal mucosa. ${ }^{1}$ Most HIV + patients develop oral thrush at least once, which is prognostic for poor outcome. ${ }^{2}$ Because loss of CD4 $+\mathrm{T}$ lymphocytes is a hallmark of AIDS, CD4 + T cells are considered key for defense against OPC. However, relatively little is known about $\mathrm{T}$-cell responses in the oral mucosa, and the specific $\mathrm{T}$-cell subset that mediates resistance to OPC has been an ongoing topic of debate.

Originally described in 1986, Thelper type 1 (Th1) and Th2 cells secrete interferon $\gamma$ (IFN $\gamma$ ) and interleukin (IL)-4 and are induced to differentiate by IL-12 and IL-4, respectively. Th17 cells were identified in 2005, and produce IL-17 (IL-17A), IL$17 F$, and IL-22 as signature cytokines., Early studies of OPC suggested that Th1 cells were key mediators of immunity, because mice deficient in the p40 subunit of IL-12 were susceptible. However, mice lacking IFN $\gamma$ were resistant to infection. ${ }^{5}$ The basis for this paradox became clear with the recognition that IL- 12 shares its p40 subunit with IL-23, which promotes Th17 maintenance and proliferation. ${ }^{4}$ In experiments designed to address this issue, we found that IL-23 - / - , IL-17RA - / - , and IL-17RC - / - mice are susceptible to OPC, whereas mice lacking the IL-12p35 subunit are resistant, strongly supporting a role for Th17 and not Th1 cells. ${ }^{6,7}$ However, experimental vaccines against Candida and other fungal infections such as Blastomyces generate both Th17 and Th1 responses, ${ }^{8-10}$ and Th17 cells and IL-17 have been implicated in immune pathology in gastric candidiasis. ${ }^{11}$ Thus, the relative importance of adaptive Th17 cells in immunity to mucosal candidiasis has not been entirely resolved. ${ }^{8,9}$

In humans, Candida-responsive CD4 + T cells express Th17 markers such as IL-17, ROR $\gamma \mathrm{t}, \mathrm{C}-\mathrm{C}$ motif chemokine receptor 6 (CCR6), and CCR4. While they sometimes co-express IFN $\gamma$, they do not express Th1-associated markers. ${ }^{12,13}$ Recurrent OPC, which is one manifestation of chronic mucocutaneous candidiasis (CMC), is characteristic of several immunodeficiency syndromes, which collectively implicate Th17 cells in

${ }^{1}$ Division of Rheumatology and Clinical Immunology, University of Pittsburgh, Pittsburgh, Pennsylvania, USA. ²Department of Pediatrics, Children's Hospital of Pittsburgh, Pittsburgh, Pennsylvania, USA and ${ }^{3}$ Department of Ophthalmology, University of Pittsburgh, Pittsburgh, Pennsylvania, USA. Correspondence: SL Gaffen (sig65@pitt.edu) 
immunity to Candida. ${ }^{14}$ In AIDS, Th17 cells are preferentially depleted, and OPC incidence tracks with CD4 loss. ${ }^{15}$ Hyperimmunoglobulin E (HIES)/Job's Syndrome patients have mutations in STAT3 (signal transducer and activator of transcription factor 3) and concomitantly reduced Th17 frequency, and they characteristically experience recurrent OPC. ${ }^{16-20}$ In addition, CMC can be caused by gain-of-function mutations in STAT1 that result in heightened cellular responses to IFN $\alpha / \beta$, IFN $\gamma$, and IL-27, all inhibitors of Th17 development. ${ }^{21,22}$ At the level of pattern recognition, mutations in the fungal pattern recognition receptor dectin-1 or its adaptor CARD9 are linked to impaired Th17 generation and CMC. ${ }^{23,24}$ Autoimmune polyendocrinopathy syndrome is also characterized by CMC and is linked to neutralizing autoantibodies against Th17 cytokines. ${ }^{25-27}$ Mutations in IL-17RA and IL-17F in humans cause CMC, independently of other co-factors. ${ }^{28}$ Together, these data support an essential role for Th17 cells in immunity to Candida in mucosal tissues.

In this study, we sought to define the nature and contribution of adaptive Th responses to oral candidiasis using a newly established recall model of OPC. We show that strong, Candida-dependent recall responses are generated in the $\mathrm{CD} 4+$ but not CD8 + T-cell compartment. There is no evidence for generation of a Th1 or IFN $\gamma$ response. Importantly, development of Th17 cells in recall infection settings promotes accelerated fungal clearance, and transfer of CD4 + $\mathrm{T}$ cells into susceptible Rag1 - / - hosts is sufficient to protect from disease. However, deficiency of $\mathrm{CD} 4+\mathrm{T}$ cells leads to compensatory IL-17 production by $\mathrm{CD} 8+$ and $\mathrm{CD} 3+\mathrm{CD} 4-$ $\mathrm{CD} 8$ - (double-negative, DN) cells and concomitant protection from OPC.

\section{RESULTS}

Pre-exposure to $C$. albicans promotes accelerated fungal clearance

To address the role of the adaptive response in OPC, we first evaluated susceptibility in Rag1 - / - mice. Wild-type (WT; C57BL/6) or Rag1-/ - mice were subjected to a 4-day sublingual infection with $2 \times 10^{7} \mathrm{CFU}$ (colony-forming units) C. albicans. ${ }^{6,29}$ As controls, IL-23 - / - or WT mice immunosuppressed with cortisone acetate were subjected to OPC. As reported previously, unmanipulated WT mice generally cleared the fungus by the end of the infection period, whereas IL-23 - / and cortisone-treated WT mice had high oral loads of Candida and concomitant weight loss (Figure 1a). Moreover, IL-23- / - mice failed to clear the infection for at least 3 weeks (Figure 1b). Rag1 - / - mice exhibited fungal loads $\sim 3$ logs higher than WT, which were statistically indistinguishable from IL-23 - / - mice, though the Rag1 - / - mice did regain some weight towards the end of the experiment (Figure 1a). These results indicate that a rearranged antigen receptor is necessary for immunity to OPC and further indicate that innate lymphoid-like cells such as those reported in certain forms of colitis do not appear to mediate immunity in this setting. ${ }^{30,31}$

Taking advantage of the fact that C. albicans is not a commensal microbe in mice, we developed a system that permits experimental separation of the effects of innate and adaptive responses (Figure 2a). WT mice were inoculated orally by means of a Candida-soaked cotton ball placed sublingually for $75 \mathrm{~min}$. Six-to-eight weeks after primary exposure, mice were re-challenged orally with Candida. As controls, mice were sham-inoculated with phosphate-buffered saline at one or both time points. On days 1, 2, and 3 following re-challenge, tongue was harvested to analyze fungal burden and cervical lymph nodes (cLN) were analyzed for cytokine production. Mice pre-exposed to C. albicans $\left(1^{\circ}+2^{\circ}\right.$ infection) had significantly lower fungal burdens $(\sim 1 \log )$ after secondary challenge than those receiving only a $1^{\circ}$ acute infection (Figure 2b). By day 3, most mice had cleared the infection, though residual fungal CFUs were still higher in mice receiving only a primary compared with secondary challenge. Therefore, previous exposure to Candida induces more efficient pathogen clearance.

To evaluate the nature of the T-cell compartment in Candida recall responses, draining cLN cells were stained for CD4, IL-17, and IFN $\gamma$ (Figure 2c,d). There were no CD4 + IL-17 + cells in sham-treated cLN. However, there was an increased frequency of CD4 + IL-17 + cells in cLN of infected mice, comprising approximately $4 \%$ by day 3 post re-challenge. There was no detectable induction of $\mathrm{CD} 4+\mathrm{IFN} \gamma+$ cells upon Candida infection, either during a first exposure or re-challenge, nor were there IFN $\gamma+$ IL-17 + double-expressors evident in either setting. There was a small increase in CD4 + IL-17 + cells in mice undergoing only a primary response. To evaluate the surface phenotype of the CD4 + IL-17 + cells, total cLN cells isolated 3 days after re-challenge were gated on $\mathrm{CD} 4$, and surface expression of CD44 and CD27 were examined relative to intracellular IL-17. CD4 + IL-17 + cells were primarily $\mathrm{CD} 27-\mathrm{CD} 44+$ (Figure 2e,f), consistent with an activated effector phenotype.

To determine whether Th17 cells have the capacity to protect from OPC, CD4 + or CD4 - cells were isolated from cLNs of mice subjected to a recall response and transferred into susceptible Rag1 - / - hosts (see Supplementary Figure S1 online). After $24 \mathrm{~h}$, mice were subjected to OPC. Mice receiving $\mathrm{CD} 4+$ but not CD4 - cells showed complete protection from OPC (Figure 2g). Notably, ill7a mRNA expression in tongue correlated with protection, indicative of a local Th17 response (Figure 2h). By contrast, there was no detectable ifng mRNA expression in the tongue following transfer of $\mathrm{CD} 4+$ cells (Figure 2h). These data suggest that Th17 cells comprise the dominant functional $\mathrm{CD} 4$ response upon Candida rechallenge.

\section{IL-17 recall response to OPC comes from the CD4 + not the CD8 + compartment}

To evaluate the nature of the T-cell response in more detail, cells isolated from cLN 3 days post re-challenge were stained for $\mathrm{CD} 3, \mathrm{CD} 4$, and $\mathrm{CD} 8$, followed by intracellular staining for IL-17 and IFN $\gamma$ (Figure 3a,b). As shown, only mice subjected to re-challenge generated significant numbers of IL-17 + cells in the $\mathrm{CD} 4+$ compartment (Figure $\mathbf{3 b}$, left). There was no 
increase in the frequency of CD8 + IL-17 + cells (Figure $3 \mathbf{b}$, left). Additionally, there was no change in the number of $\mathrm{CD} 4+\mathrm{IFN} \gamma+$ cells (Figure $\mathbf{3 b}$, right). There was a small increase in IFN $\gamma+$ cells in the $\mathrm{CD} 8+$ compartment, (Figure $3 \mathbf{b}$, right), but this was transient and not sustained at 5 days post-infection (see Supplementary Figure S2a online). There was a low baseline level of IL-17 + cells in the CD3-negative population, which did not change after infection (see Supplementary Figure S2b online).

\section{CD4 + IL-17 recall response to OPC is antigen-specific}

To confirm that induction of cytokines is Candida-specific, cLN cells were harvested 3 days after re-challenge and stimulated in vitro with heat-killed (HK) C. albicans for
5 days. Supernatants were evaluated for IL-17 and IFN $\gamma$ by enzyme-linked immunosorbent assay. Consistent with the intracellular cytokine staining data (Figure 3a,b), high levels of IL-17 $\left(\sim 500 \mathrm{pg} \mathrm{ml}^{-1}\right)$ were produced in mice exposed to Candida during a secondary response but not in sham-infected mice and only modestly in $1^{\circ}$ infected mice (Figure $3 \mathbf{c}$, left). Production of IL-17 was blocked by anti-CD $4^{32}$ and anti-MHC Class II Abs (anti-major histocompatibility complex Class II antibodies), indicating that antigen presentation is required. To further verify that IL-17 production is antigen-specific, LN cells from infected mice were cultured in vitro with a peptide derived from the Candida adhesins Als1 (agglutinin-like sequence 1) and Als3, recently shown to be an epitope recognized by $\mathrm{CD} 4+\mathrm{T}$ cells. ${ }^{33}$ Treatment with the Als $1 / 3$ peptide (pALS)
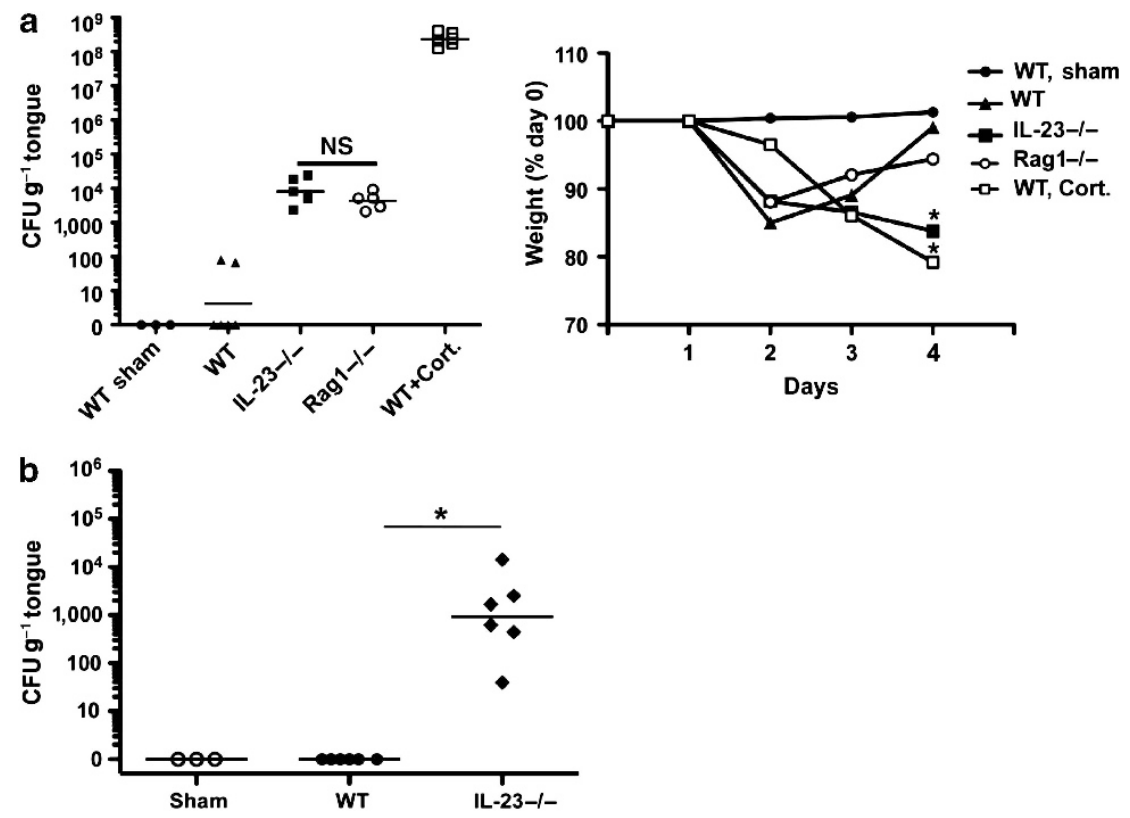

Figure 1 Rag1 - / - mice are susceptible to oropharyngeal candidiasis (OPC).Wild-type (WT), interleukin (IL)-23 - / - , or Rag1 - / - mice were subjected to sublingual infection with Candida albicans, and fungal load in tongue was assessed by plating onto YPD (yeast peptone dextrose) and colony enumeration in triplicate. Sham mice were inoculated with phosphate-buffered saline (PBS) only. Cortisone-treated (Cort.) mice were given 225 mg kg ${ }^{-}$ cortisone acetate at days $-1,+1$, and +3 relative to infection. colony-forming units (CFU) $\mathrm{g}^{-1}$ tongue tissue is indicated with geometric mean (bar). Weight loss (average per cohort) during infection is shown as a percentage of starting weight at day 0 . Data represent two independent experiments. ${ }^{\star} P<0.05$ compared with WT mice infected with Candida. B. IL-23 - / - mice remain persistently infected with $C$. albicans. The indicated mice were subjected to $1^{\circ}$ infection. Twenty-one days later, fungal load in tongue was assessed by plating on YPD and colony enumeration in triplicate. ${ }^{\star} P<0.05$ compared with WT.

Figure 2 Adaptive Candida albicans-responsive Thelper type 17 (Th17) cells accelerate fungal clearance. (a) New re-challenge oropharyngeal candidiasis (OPC) infection model. Diagram of infection timeline. (b) Re-challenge is associated with accelerated Candida clearance. Wild-type (WT) mice were subjected to a $1^{\circ}$ infection with Candida or phosphate-buffered saline (PBS; sham). After 6 weeks, mice were re-challenged with $C a n d i d a\left(1^{\circ}+2^{\circ}\right.$ infection) or PBS. Mice were killed at days 1, 2, and 3 post re-challenge, and fungal load in tongue was assessed by plating and colony enumeration in triplicate. Data are pooled from two replicate experiments. (c) CD4 + Th17 but not Th1 cells are generated upon Candida re-challenge. cervical lymph nodes (cLN) cells from the experiment described in $\mathbf{b}$ were isolated 1-3 days after re-challenge and stained for CD4, interleukin (IL)-17, and interferon $\gamma$ (IFN $\gamma$ ). Lymphocytes (determined by forward and side scatter profiles) were gated on CD4 + , and IL-17+ and IFN $\gamma+$ cell frequencies are depicted. Representative FACS (fluorescence-activated cell sorter) plots are shown. (d) Summary of data from panel c. Note that data are normalized to intracellular cytokine staining (ICS) staining from isotype controls. (e, f) IL-17+ cells exhibit an activated phenotype. cLN cells were isolated 3 days after $1^{\circ}$ or re-challenge and gated on CD 3 and CD4. Surface expression levels of CD44 and CD27 were examined relative to intracellular IL-17. Data from mice subjected to recall are summarized in panel f. ${ }^{*} P<0.05$ (g) CD4 + T cells are sufficient to confer immunity to OPC in Rag1 $-/-$ mice. WT mice were subjected to sham or re-challenge $\left(1^{\circ}+2^{\circ}\right)$. On day 3 after re-challenge, CD4 + and CD4 - cells were harvested from CLN by magnetic sorting. $1 \times 10^{7} \mathrm{CD} 4+$ or $2 \times 10^{7} \mathrm{CD} 4-$ cells were transferred into Rag1 - / - recipients. After $24 \mathrm{~h}$, Rag1 - / - mice were infected with Candida, and weight loss monitored for $5 \mathrm{~d}$ (right). Fungal load in tongue was assessed at day 5 (left). ${ }^{*} P<0.05$ by $t$-test with Mann-Whitney correction or analysis of variance; ns, not significant. (h) IL-17 but not IFN $\gamma$ is expressed locally upon transfer with re-challenged CD4 + cells. Rag1 - / - mice were adoptively transferred with (or without) CD4 + cells from WT mice given a sham infection or a recall $\left(1^{\circ}+2^{\circ}\right)$ infection. Expression of il17a and ifng mRNA in tongue were assessed in by quantitative PCR. Note that these samples are from a different experiment than shown in panel $\mathbf{g}$. ${ }^{*} P<0.05$ by $t$-test with Mann-Whitney correction. 
triggered IL-17 production, though not to the same magnitude as HK Candida, and was blocked by anti-MHC Class II Abs (Figure 3c). Therefore, the Th17 response is antigen-specific. Unexpectedly, there was a modest but reproducible CD4dependent induction of IFN $\gamma$ following treatment with $\mathrm{HK}$ Candida in re-challenged mice, ranging from $\sim 15$ to $100 \mathrm{pg} \mathrm{ml}^{-1}$, depending on experiment, Figure 3d. The induction of IFN $\gamma$-producing cells was slightly increased in re-challenged mice compared with mice receiving only a primary infection and was blocked with anti-CD4 or anti-MHC II Abs. However, there was no detectable IFN $\gamma$ production after in vitro challenge with pALS. Although inducible IFN $\gamma$ following in vitro challenge contrasts with the apparent lack of a Th1 response in cells taken immediately ex vivo measured a

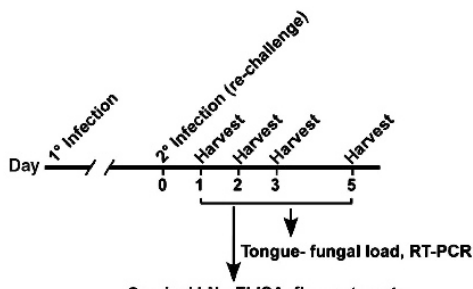

Cervical LN - ELISA, flow cytometry

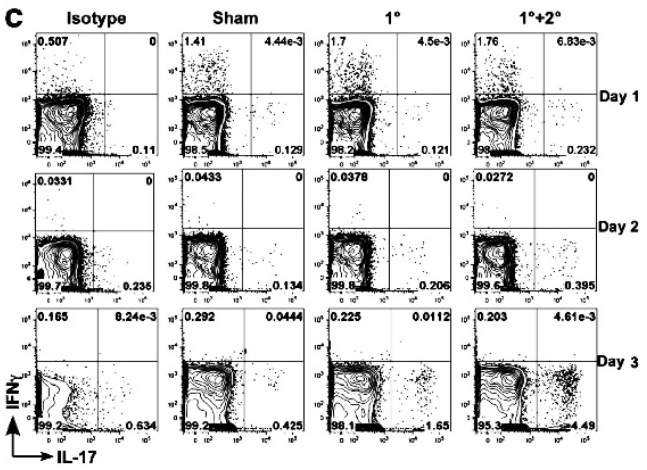

e

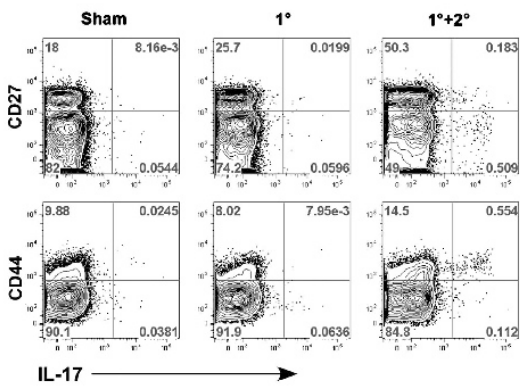

g

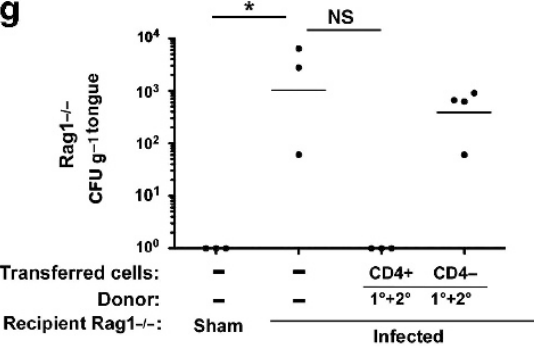

h

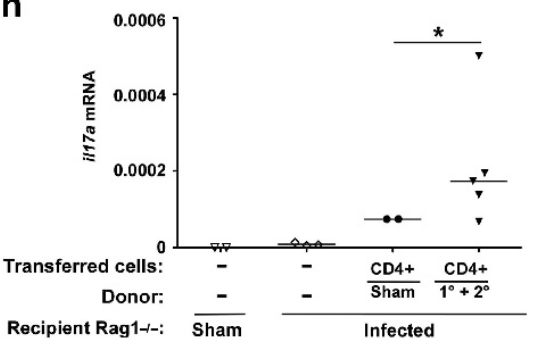

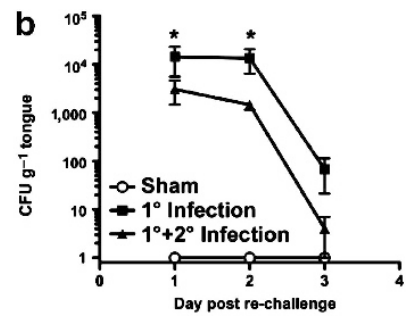

d
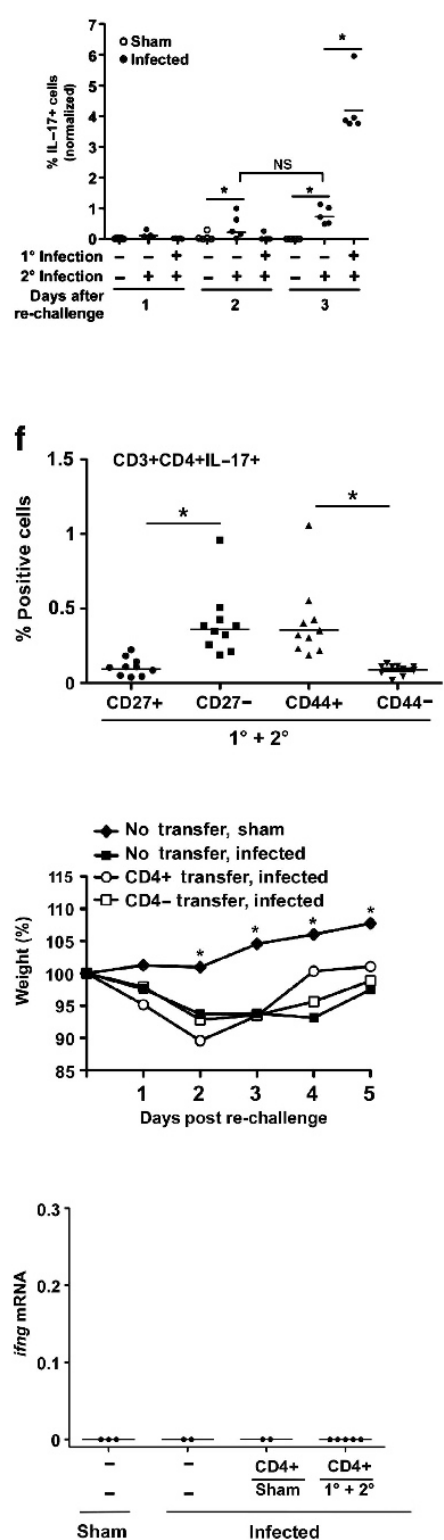
by flow cytometry, it is most likely that Th1 cells are induced during infection but at levels below the detection limit of flow cytometry. Together, these data indicate that the response to oral Candida infection is primarily IL-17 driven, though we cannot entirely rule out a role for IFN $\gamma$. Moreover, generation of a strong CD $4+$ Th 17 recall response promotes accelerated oral clearance of C. albicans.

\section{Compensatory sources of IL-17 in CD4-deficient mice}

To determine whether generation of $\mathrm{CD} 4+\mathrm{Th} 17$ cells is necessary for clearance of Candida from the oral cavity, WT or $\mathrm{CD} 4-/$ - mice were subjected to re-challenge and evaluated for symptoms of OPC, including weight loss and oral fungal burden. CD4-/- mice were resistant to OPC, as they regained weight equivalently to WT mice after infection (Figure 4a) and had no detectable oral fungal burden (Figure $4 \mathbf{a}$, inset). To evaluate the possibility that IL-17 might be produced from a compensatory source in CD4deficient mice, cLN cells from WT and CD $4-/-$ mice were analyzed for cytokines 5 days after re-challenge. In WT mice, $\mathrm{CD} 4+$ but not $\mathrm{CD} 8+\mathrm{T}$ cells expressed IL-17 during rechallenge (Figure $4 b$ ). However, in re-challenged CD4- / mice, CD8 + T cells produced abundant IL-17 (Figure $\mathbf{4 b}, \mathbf{c}$ ). The frequency of IFN $\gamma$-expressing CD8 + cells was similar in WT and CD4 - / - mice (Figure 4c, right), further confirming that IFN $\gamma$ responses do not seem to have a role in protection. Although somewhat variable, levels of IL-17 from the CD8 compartment in $\mathrm{CD} 4-/$ - mice were usually comparable with that of the CD4 compartment in WT mice (Figure 4d left, and data not shown). IL-17 secretion from in vitro-stimulated cLN cells was observed only during $2^{\circ}$ challenge (Figure $4 \mathbf{d}$, left). There was a weak but significant increase in the IFN $\gamma$ response as well (Figure 4d, right). There was a low frequency of IL-17producing cells in the CD3-negative population in both WT and CD4 - / - mice, which did not change following infection (see Supplementary Figure S2 online).

As the resistance of $\mathrm{CD} 4-1-$ mice to $C$. albicans re-challenge correlates with compensatory IL-17 production by $\mathrm{CD} 8+\mathrm{T}$ cells, we tested the susceptibility of CD $8-/-$ mice to OPC. Like CD4-/- mice, CD8 - / - mice were resistant to OPC upon re-challenge, based on weight gain after infection and the complete absence of an oral fungal load (Figure 5a). Consistently, equivalent numbers of CD4+ IL$17+$ cells were present in CLN of CD8 - / - and WT mice subjected to re-challenge but not in cLN of mice that only received a $1^{\circ}$ infection, whereas $\mathrm{CD} 4+\mathrm{IFN} \gamma+$ cell frequencies were unchanged (Figure 5b). High levels of IL-17 were induced after in vitro culture with HK Candida (Figure 5c), which was blocked with anti-CD4 Abs (Figure 5c, left). Although the difference between IL-17 levels in the $1^{\circ}$ and $1^{\circ}+2^{\circ}$ in vitro cultures did not reach statistical significance, this was likely due to a single outlier in the $1^{\circ}$ sample, and the overall trend strongly resembled what was observed in the CD4 compartment in WT mice. There was induction of a weak IFN $\gamma$ response in $\mathrm{CD} 8-1-$ mice during both $1^{\circ}$ and $2^{\circ}$ responses (Figure $\mathbf{5 c}$, right).

\section{Functional compensation by Tc17 and DN cells in CD4 - I-} mice

We next determined whether the CD8 + "Tc17" cells from rechallenged CD4-deficient hosts were capable of mediating immunity to OPC. To that end, Rag1 $-/-$ mice were adoptively transferred with $\mathrm{CD} 4+$ cells, $\mathrm{CD} 8+$ cells or CD4 - CD8 - (DN) cells derived from WT or CD4-/ donors (see Supplementary Figure S1b online). Cells from sham-infected WT donors did not provide any protection from OPC. As expected, CD4 + cells but not CD8 + or DN cells from infected WT donors were protective. Also as predicted, $\mathrm{CD} 8+$ cells from infected $\mathrm{CD} 4-/-$ mice provided detectable (although variable) protection from OPC. Unexpectedly, the DN population from $\mathrm{CD} 4-/-$ mice were also protective, even more consistently than the $\mathrm{CD} 8+$ population (Figure 6a). Based on these observations, we evaluated IL-17 expression in the DN population from $\mathrm{WT}$ and $\mathrm{CD} 4-/-$ mice. IL-17 was indeed expressed in the DN cells, but only in the context of CD4 deficiency (Figure 6b).

To verify that the transferred cell populations were mediating a local response in the oral mucosa, we performed quantitative PCR on tongue mRNA samples. As shown, CD3e expression in tongue correlated with protection from OPC, suggesting that the relevant effector populations were being recruited and/or expanding in situ (i.e., $\mathrm{CD} 3+\mathrm{CD} 4+$ cells from WT donors and $\mathrm{CD} 3+\mathrm{CD} 8+$ and $\mathrm{CD} 3+\mathrm{CD} 4-$ CD8 - (DN) cells from CD4 $-/-$ donors) (Figure 6c). A similar observation was made for CD4 and CD8 mRNA expression, which correlated with the protective IL-17producing populations (Figure $\mathbf{6 c}$ ). Collectively, these results demonstrate that, under normal circumstances, CD4 + Th17 cells and not CD8 + or DN cells mediate IL17-dependent immunity during adaptive responses to OPC. However, in conditions of CD4-deficiency, CD8 "Tc17" cells and DN cells can serve as alternate sources of IL-17 that are able to promote effective immunity to C. albicans. This finding illustrates the highly flexible nature of the anti-fungal immune response.

\section{DISCUSSION}

The goal of this study was to determine the nature of long-term T-cell response to OPC taking advantage of the fact that mice are not normally colonized with Candida and do not have baseline levels of Candida-reactive T cells. Upon re-challenge, we observed bona fide antigen-specific Th17 responses generated against Candida. There was no evidence for a $\mathrm{CD} 8+\mathrm{IL}-17+(\mathrm{Tc} 17)$ response, nor were CD3-IL-17+, $\mathrm{CD} 4+\mathrm{IFN} \gamma+, \mathrm{CD} 8+\mathrm{IFN} \gamma+$, or IFN + IL-17 + doubleexpressing $\mathrm{T}$ cells detectable by flow cytometry during recall (Figures 2 and $\mathbf{3}$ ). There was, however, a small but reproducible induction of IFN $\gamma$ following in vitro challenge with $\mathrm{HK}$ Candida (Figure 3d), indicating that Th1 cells are generated at low levels and may potentially participate in antifungal responses. Generation of this Th17-dominant response correlates with improved clearance of Candida, and CD4+ 
$\mathbf{a}$
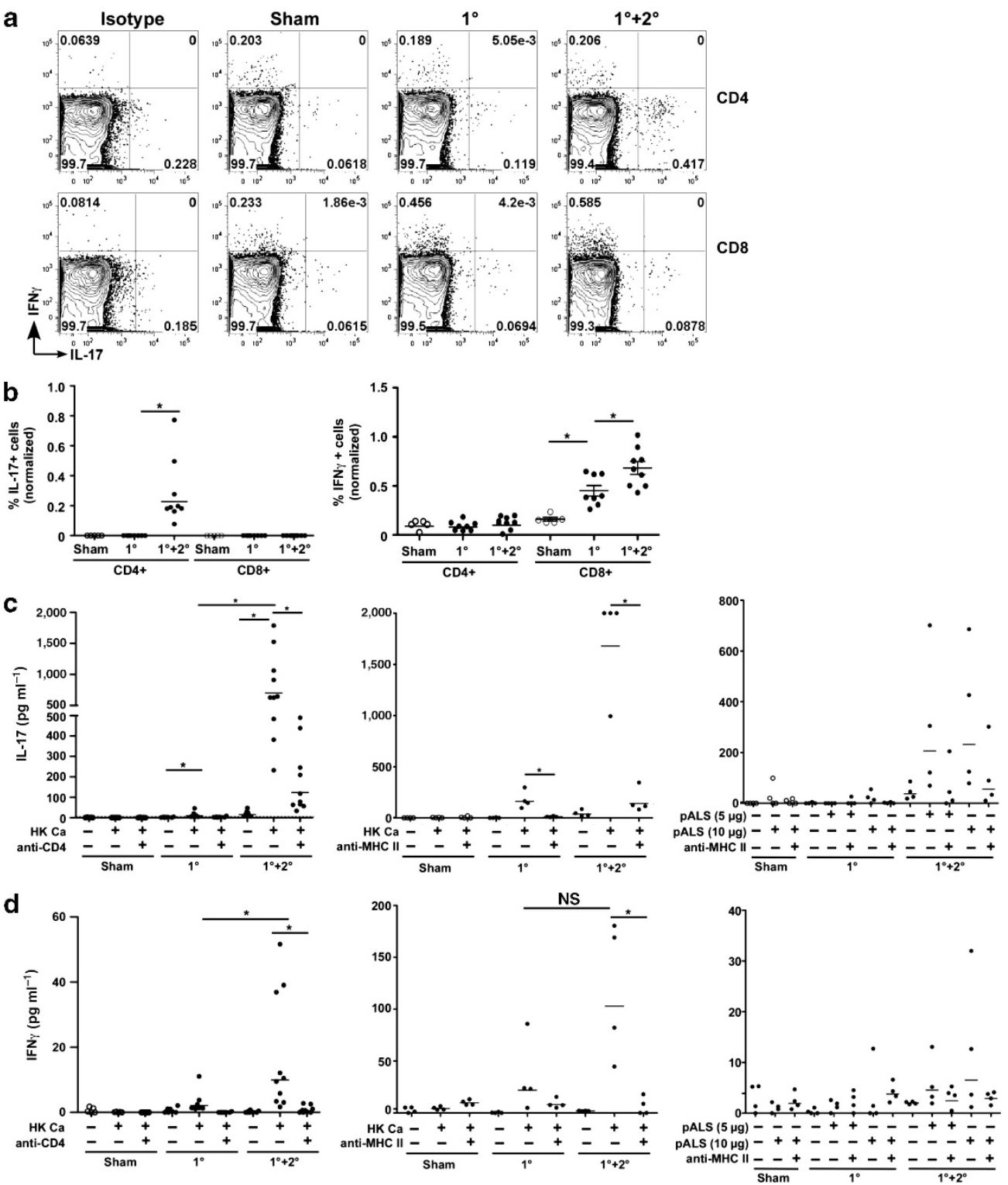

Figure 3 Interleukin (IL)-17 is produced by CD4 + but not CD8 + T cells in cervical lymph nodes (cLN) upon re-challenge with Candida. (a, b) CD4 but not CD8 IL-17 + T cells are induced following re-challenge. Wild-type (WT) mice were subjected to the re-challenge model as in Figure 2a. On day 3 post re-challenge, CLN cells were gated on CD3 + lymphocytes and CD4 + or CD8 + populations, and IL-17+ and interferon $\gamma+($ IFN $\gamma+$ ) cell frequencies were assessed by intracellular cytokine staining (ICS). Representative plots are shown. (b) Summary of data from panel a, indicating percentages of IL-17 + (left) or IFN $\gamma+$ (right) cells from CD4 + and CD8 + compartments. Data are normalized to isotype control staining and are representative of two experiments. (c, d) IL-17 and IFN $\gamma$ levels in cLN cells following Candida re-challenge. Cells from cLN were isolated 3 d post re-challenge from the indicated mice and were then cultured in vitro for 4-5d \pm heat-killed $C$. albicans (HK Ca; left and middle panels) or the ALS1/3 peptide (right) in the presence or absence of anti-CD4 neutralizing Abs (left) or anti-MHC Class II Abs (anti-major histocompatibility complex Class II antibodies; middle and right). ${ }^{32}$ IL-17A or IFN $\gamma$ was assessed by enzyme-linked immunosorbent assay. ${ }^{*} P<0.05$ by Mann-Whitney $t$-test.

T cells were sufficient to confer immunity to OPC in susceptible Rag1-/ - hosts (Figures 2g,h and 6), demonstrating a functional role for Candida-specific Th17 cells.

The finding that adaptive Th17 responses provided $\mathrm{a} \sim 1 \log$ reduction of oral fungal burden is significant (Figure 2b), while highlighting challenges associated with improving antifungal immunity. There are presently no vaccines to any fungal organisms, so it is imperative to define correlates of immunity that could provide clinical benefit. The only experimental vaccine to Candida where efficacy has been evaluated in OPC is based on the cell wall adhesin Als3, which conferred $<1 \log$ protection upon challenge. ${ }^{34}$ Notably, we observed a Th17specific recall response to this protein following Candida infection (Figure 3c). During disseminated candidiasis, a vaccine consisting of DCs transfected with $C$. albicans RNA caused only a fivefold decrease in fungal burden. ${ }^{35}$ Similarly, vaccination with antibody-inducing cell wall preparations of Candida resulted in, at most, a $\sim 2$ log decrease in fungal burden following intravenous or intravaginal challenge. ${ }^{36}$ Thus, there is clearly a need for optimization of antifungal immune responses, all the more challenging given that the target population for such vaccines is usually 


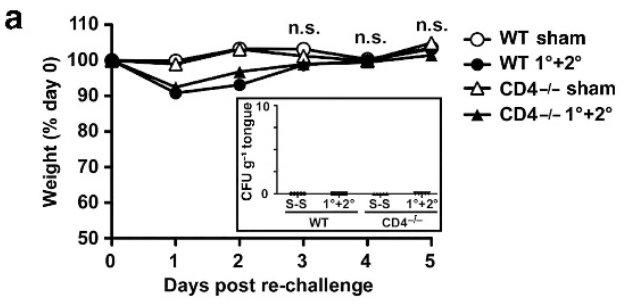

b
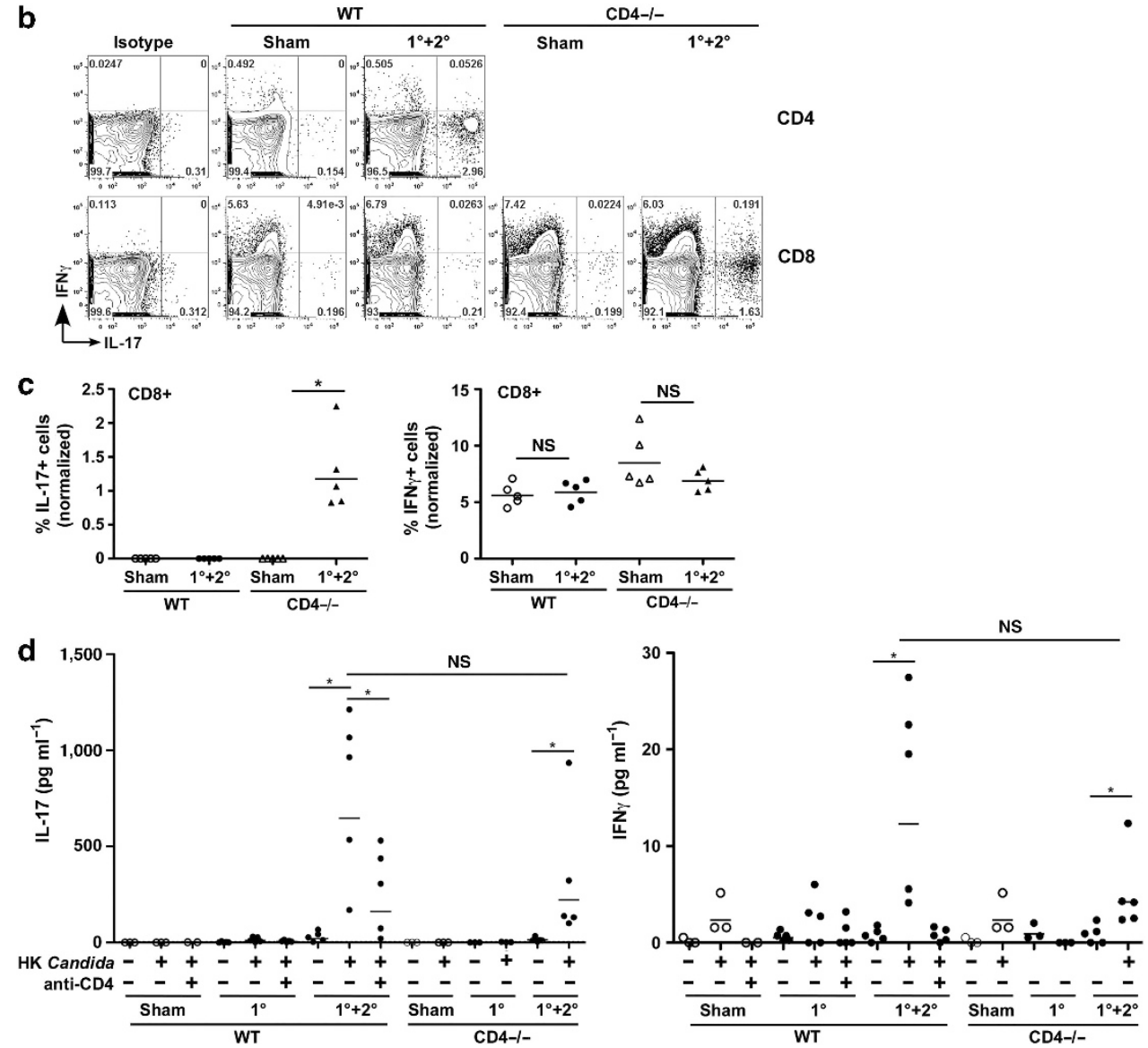

Figure 4 CD4-deficient mice are resistant to re-challenge with Candida, which is associated with compensatory interleukin (IL)-17 from CD8 + T cells. (a) CD4 - / - mice are resistant to oropharyngeal candidiasis (OPC). Wild-type (WT) or CD4 - / - mice were subjected to the OPC re-challenge model. Daily weight measurements post re-challenge are indicated as a percentage of starting weight. NS, not significant by analysis of variance. Inset: Fungal burden on day 5 after re-challenge is indicated. (b, $\mathbf{c})$ CD $4-/$ - but not WT mice induce IL-17 + CD8 + T cells upon re-challenge. WT or CD4 - / - mice were subjected to the re-challenge model. On day 5 post re-challenge, cervical lymph nodes (CLN) cells were gated on CD3 + lymphocytes and CD4 + or CD8 + populations, and IL-17 + and interferon $\gamma+(\mathrm{IFN} \gamma+)$ cell frequencies are depicted in CD4 + (WT only) or CD8 + cells. Representative plots are shown. (b) Summary of flow cytometry data from panel a, indicating percentages of IL-17 + (left) or IFN $\gamma+$ (right) cells from CD4 + and CD8 + compartments. Data are normalized to isotype controls and are representative of two independent experiments. (d) CD4 - / - and WT mice produce IL-17 upon re-challenge. Cells from CLN were isolated $3 \mathrm{~d}$ post re-challenge and cultured in vitro for $5 \mathrm{~d} \pm$ heat-killed (HK) Candida albicans \pm anti-CD4 neutralizing Abs. Concentrations of IL-17A or IFN $\gamma$ were assessed by enzyme-linked immunosorbent assay.

immunocompromised (e.g., HIV/AIDS patients). Although our findings support the idea that Candida-specific Th17 cells are protective during acute re-infection, the time frames used in this study were too brief to demonstrate true immunological memory, which will be essential for any effective immunization strategy. Further efforts to probe the issue of Th17 memory generation and maintenance are therefore still warranted.

An unexpected finding was compensatory IL-17 production in the context of CD4-deficiency. Whereas in WT mice, IL-17 was only made by $\mathrm{CD} 4+\mathrm{T}$ cells during recall Candida infections, both CD8 + and DN T cells from CD $4-/-$ mice expressed IL-17 upon re-challenge (Figures 4 and 6). This compensatory phenotype helps explain the resistance of CD4 $-/-$ mice to OPC. The DN cells in the CD4-/mice are likely to be MHC Class II-restricted T cells that have been previously shown to exist in high numbers in CD4deficient mice, ${ }^{37}$ although to our knowledge they have not previously been shown to secrete IL-17. Compensatory CD8 T-cell responses in CD4-deficiency have been observed in HIV/ SIV (simian immunodeficiency virus) infection. ${ }^{38}$ For example, in HIV patients with low CD 4 counts, IL- $17+\gamma \delta+\mathrm{T}$ cells reactive to Candida are expanded. ${ }^{39}$ Both Th17 and Tc17 cells 
a

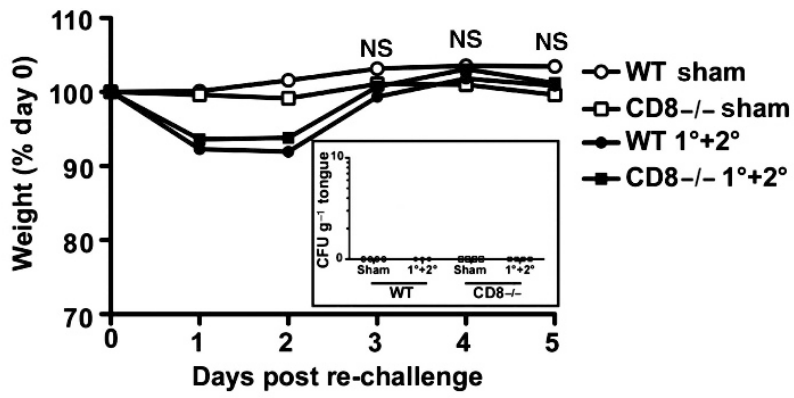

b

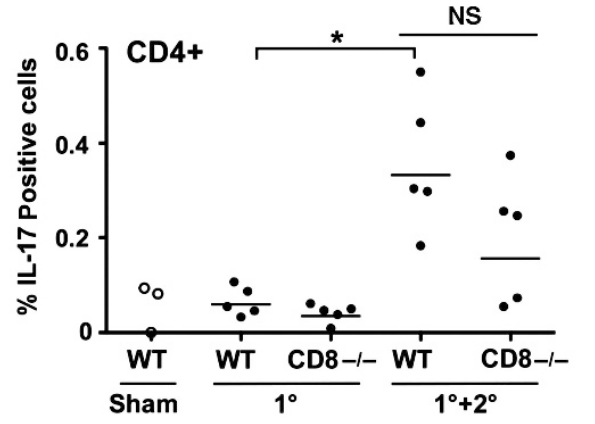

C

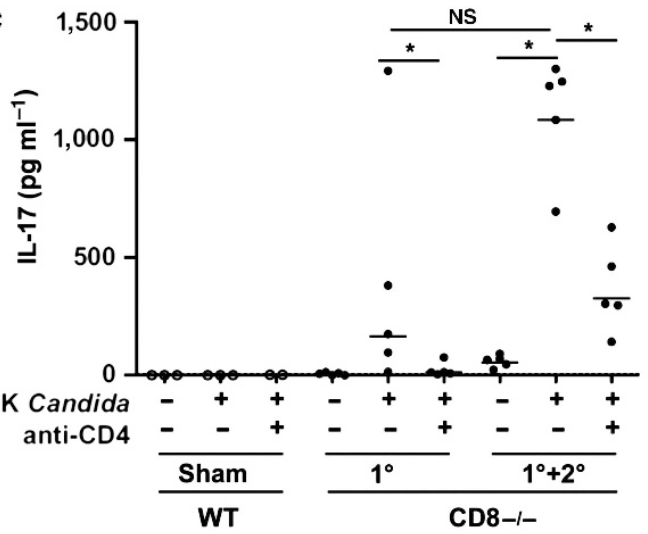

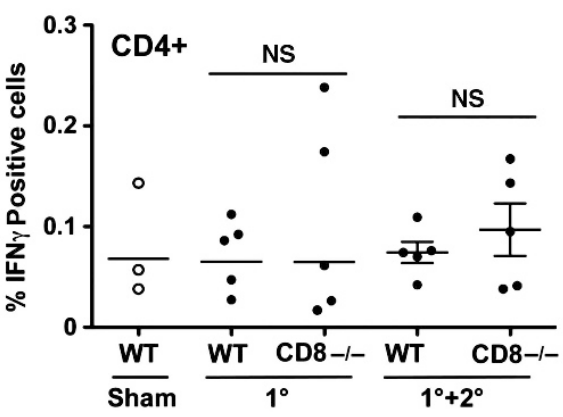

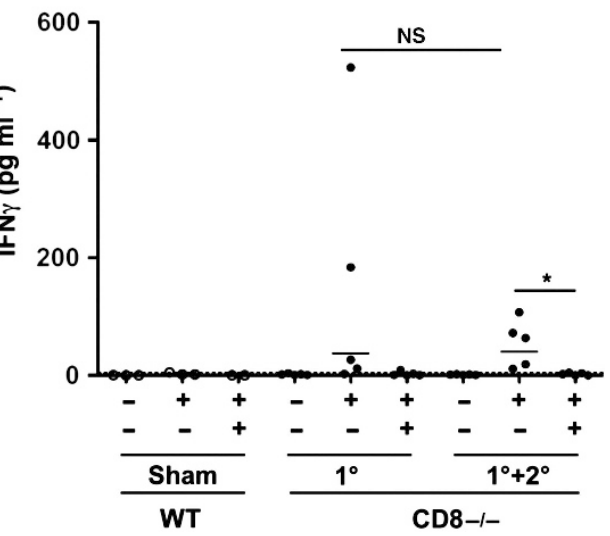

Figure $5 \mathrm{CD} 8$ - / - mice respond to Candida similarly to wild-type (WT). (a) CD8 - / - mice are resistant to oropharyngeal candidiasis (OPC). WT or CD8 - / - mice were subjected to the OPC re-challenge model. Daily weight measurements are indicated as a percentage of starting weight. NS, not significant by analysis of variance. Inset: Fungal burdens on day 5 post re-challenge are indicated. (b) CD 8 - / - mice enhance T helper type 17 (Th17) cells but not Th1 cells upon re-challenge. On day 3 post re-challenge, cervical lymph nodes (cLN) cells from WT or CD8 - / - mice were gated on lymphocytes, CD3 + and CD4 + cells. The frequency of interleukin (IL)-17+ and interferon $\gamma+($ IFN $\gamma+$ ) cells among the CD4 + population is shown. Data are normalized to isotype controls. ${ }^{*} P<0.05$ by $t$-test with Mann-Whitney correction. (c) CD $8-/-$ mice secrete IL-17 upon re-challenge with Candida in a CD4-dependent manner. Cells from cLN of indicated mice were isolated $3 \mathrm{~d}$ post re-challenge and cultured in vitro for $5 \mathrm{~d} \pm$ heat-killed (HK) C. albicans \pm anti-CD4 neutralizing Abs. IL-17A or IFN $\gamma$ were assessed by enzyme-linked immunosorbent assay. Note that this is from the same experiment presented in Figure $4 \mathbf{d}$. ${ }^{*} P<0.05$ by Mann-Whitney $t$-test.

are observed in SIV-infected rhesus macaques, with preferential loss of Th17 but not Tc17 in early phases of disease. ${ }^{40}$ Compensatory CD $8+$ "Tc17" cells were also recently described in a model of immunity to Blastomyces dermatitidis. In that system, Blastomyces-specific Tc17 cells were induced upon vaccination in the absence of CD4 + T-cell help and protected mice from lethal challenge. Moreover, vaccinationdependent influx of neutrophils into the lungs correlated with protection and was dependent on vaccine-induced Tc17 cells. ${ }^{10}$

The regulation of Th17 memory cells in settings of infection is beginning to be understood. A recent proteomics study of Candida epitopes identified MHC Class II-bound peptides derived from Candida cell wall adhesins, Als1 and Als3. Th17 cells recognizing these antigens were found in significant numbers in both human and murine memory $\mathrm{T}$-cell repertoires. ${ }^{33}$ Consistently, we saw reactivity to this Als $1 / 3$ peptide in Th17 cells from Candida re-challenged mice (Figure 3c). Th17 cells are challenging to understand due to their plasticity in vivo, ${ }^{41}$ as they frequently interconvert with Th1 cells or Tregs. ${ }^{42,43}$ Using a lineage-tracking system to track the fate of IL-17-expressing cells, Stockinger's group reported that Th17 cells convert to dual-expressing IL-17 + IFN $\gamma+$ "Th1/17" cells and IL-17-IFN $\gamma$ Th1 cells in settings of chronic autoimmunity. However, they observed minimal interconversion in the setting of acute dermal candidiasis, where $\gamma \delta$-TCR + (T-cell receptor) cells were found to predominate. ${ }^{42}$ We found that the Th17 recall response is stable and specific, as there was little generation of either IL-17/IFN $\gamma$ double-expressing cells or 
a
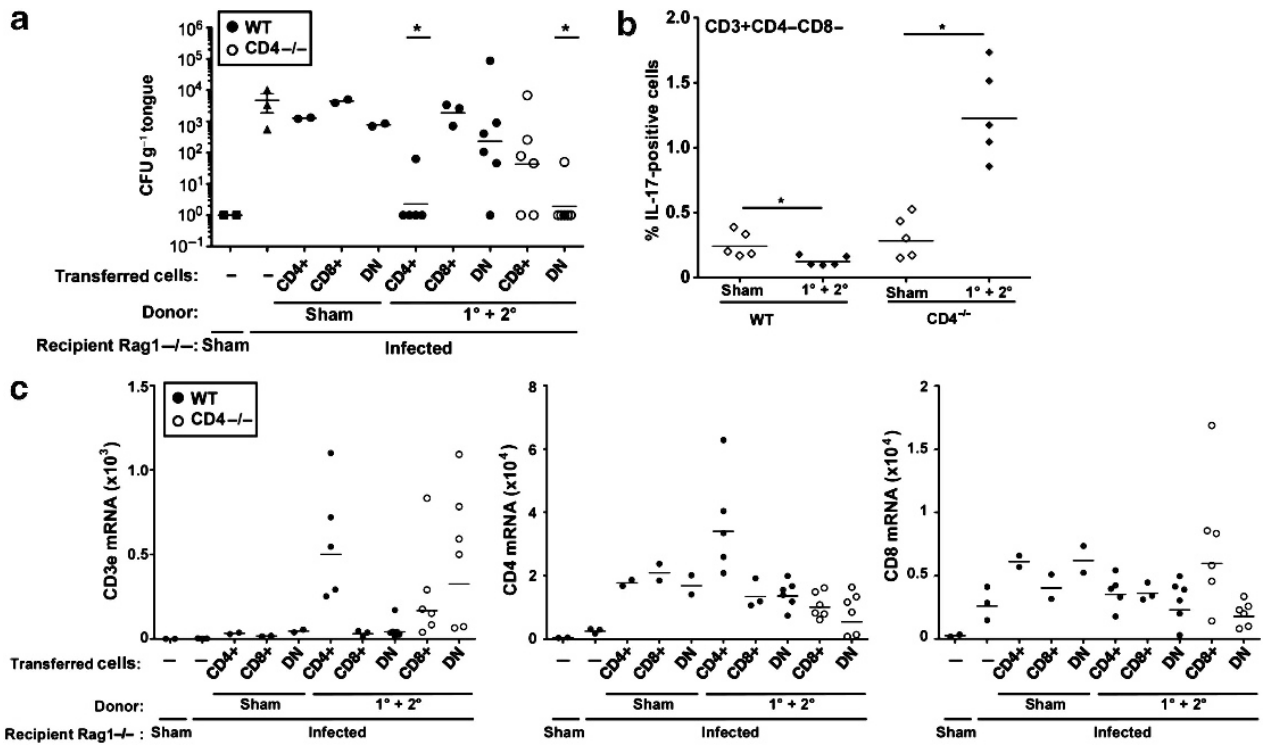

Figure $6 \mathrm{CD} 8+$ and double-negative (DN) cells protect from oropharyngeal candidiasis (OPC) in the context of CD4 deficiency. (a) Wild-type (WT; filled circles) or CD4 - / - mice (open circles) were subjected to sham infection or re-challenge $\left(1^{\circ}+2^{\circ}\right.$ infections). CD4,+ CD $8+$, and DN cells were purified by magnetic sorting and transferred into Rag1-/ - recipients, which were then subjected to OPC or sham infections, as indicated. Fungal load after 4 days was assessed by plating. (b) CD3 + CD4 - CD8 - (DN) cells express interleukin (IL)-17 upon re-challenge in CD4 - / - but not WT mice. Percentage of DN cells expressing IL-17 by intracellular cytokine staining (ICS) is indicated. * $P<0.05$ by Mann-Whitney $t$-test. (c) Expression of T-cell markers in tongue correlates with disease protection. Rag1 $-/$ - recipients were adoptively transferred with the indicated cell populations $\left(\mathrm{CD} 4+, \mathrm{CD} 8+\right.$, or DN) from WT sham or infected mice. Tongue mRNA was evaluated for $c d 3 e, c d 4$ or cd8 by quantitative PCR (multiplied by $10^{4}$ ). Each data point indicates a single mouse analyzed in triplicate.

IFN $\gamma$-expressing cells, and no IFN $\gamma$ was detected in the oral mucosa upon adoptive transfer of primed CD4 $+\mathrm{T}$ cells into Rag1 - / - hosts (Figure 2h). This agrees with our observation that IL-23 - / - and IL-17RA - / - mice remain chronically infected (Figure $\mathbf{1})^{6}$, though contrasts with a report that Candida-responsive Th17 cells in humans often co-express IFN $\gamma$, particularly after in vitro culture. ${ }^{13}$

Resistance to OPC in CD4 - / - and CD8 - / - mice differs from the overt disease seen in IL-23- / - and IL-17R - / mice at both short and long time points ${ }^{6}$ (Figure 1). These findings suggest the existence of a powerful innate IL-17 response, which is presumably still operative during adaptive responses. In that regard, many innate sources of IL-17 have been identified, including NKT (natural killer T cells), $\gamma \delta \mathrm{T}$, and innate lymphoid-like cells. ${ }^{44,45}$ Indeed, models of dermal candidiasis implicate innate $\gamma \delta \mathrm{T}$ cells rather than adaptive IL-17-expressing cells. ${ }^{42,46}$ However, surprisingly little is known about oral mucosal immunity in mice or how accurately such responses translate to humans. Mice are coprophagic and may routinely mount powerful antimicrobial responses to prevent disease transmission from fecal matter. Saliva is another important facet of oral innate immunity; IL-23 - / - and IL-17RA - / - mice as well as HIES patients (who are Th17 deficient) have defects in salivary anti-Candida activity, associated with reduced expression of antimicrobial proteins such as defensins and histatins. ${ }^{6}$ An intriguing new report indicates that monocytes exhibit epigenetic modifications following Candida infection that contributes to a protective response. ${ }^{47}$ Therefore, immunity to OPC involves orchestration of both innate and adaptive sources of IL-17.
Regardless of source, IL-17 is essential for host defense against Candida infections. ${ }^{26,48,49}$ The mechanisms by which IL-17 mediates antifungal immunity are not fully delineated, but a major function of IL-17 is to mobilize neutrophils. IL-17 induces expression of neutrophil-recruiting cytokines and genes such as G-CSF (granulocyte colony-stimulating factor), CXCL1 (C-X-C motif chemokine ligand 1), CXCL2, and CXCL5, and neutrophil influx correlates with disease protection. ${ }^{50,51}$ Intriguingly, Candida appears to evade the IL-17 response through a virulence factor that skews towards a Th1 phenotype through manipulation of the IDO (indoleamine$(2,3)$-dioxygenase) pathway, supporting the idea that IL-17 is vital for defense. ${ }^{52}$

Although there are parallels between instinal and oral mucosa, there are key differences. The oral cavity has no $\mathrm{M}$ cells or Peyer's patches. ${ }^{53}$ The composition of the oral microbiome is also unique, ${ }^{54}$ and it is not known whether particular species of oral microbes dictate Th17 cell levels in the mouth as they do in the intestine. ${ }^{55}$ We do not detect basal levels of IL-17 in tongue even by sensitive reverse transcriptase-PCR methods, suggesting that oral flora does not promote a tonic level of IL-17expressing cells (data not shown). It is noteworthy that IL-17 and IL-23 appear to be pathogenic in a model of gastric candidiasis, ${ }^{11,56}$ though gastric infection with Candida in humans is not a clinical problem. In vaginal candidiasis, the role of the Th17/IL-17 pathway is unclear, with some evidence supporting a role for IL-17, ${ }^{57}$ but studies in mice suggesting that innate effectors such as $\mathrm{S} 100$ proteins and annexins are more important. ${ }^{1,58,59}$ This dichotomy of IL-17-dependent protection versus pathology in different models of mucosal 
candidiasis illustrates the point that lessons from the gut mucosa cannot always be applied to the mouth.

\section{METHODS}

Mice. Mice were on the C57BL/6 background and were age- and sex-matched. IL-23p19-/- mice were provided by Genentech (San Francisco, CA) and bred in-house. All other mice were from the Jackson Laboratory (Bar Habor, ME). Protocols were approved by the University of Pittsburgh IACUC, and adhered to guidelines in the Guide for the Care and Use of Laboratory Animals of the NIH.

OPC recall infection model. Mice aged 5-6 weeks (minimum $n=3$ per cohort) were inoculated sublingually with a $0.0025 \mathrm{~g}$ cotton ball saturated in a C. albicans suspension of $2 \times 10^{7} \mathrm{CFU} / \mathrm{ml}$ for $75 \mathrm{~min}$. under anesthesia. ${ }^{6,29}$ Six weeks after the primary infection, mice were re-challenged by the same procedure. The oral cavity was swabbed immediately before each infection and streaked on YPD (yeast peptone dextrose) to verify the absence of Candida. One-to-five days post re-challenge, the tongue was homogenized on a Gentle MACS Dissociator (Miltenyi Biotec Auburn, CA) and plated on YPD-AMP for $48 \mathrm{~h}$ at $30^{\circ} \mathrm{C}$ followed by colony enumeration in triplicate. For cell transfer experiments, cLN cells were harvested from WT mice 3 days after re-challenge and pooled. CD4 + cells were isolated by positive selection using Miltenyi Biotec CD4 (L3T4) MicroBeads and LS columns. The resulting CD4+, CD4-, CD8 + or CD4-CD8(DN) fractions were transferred into Rag1 - / - recipients (stock number 002216) intraperitoneally, and $24 \mathrm{~h}$ later, mice were infected orally as described above. A total of $10^{7} \mathrm{CD} 4+$ cells and $2 \times 10^{7}$ CD4 - cells were transferred in $200 \mu$ l phosphate-buffered saline. For sham transfers, transferred cells were from total body LN. Data were analyzed on Graphpad Prism (v. 5) using t-tests with Mann-Whitney correction $(P<0.05$ considered significant).

Culture of $C$. albicans and stimulation in vitro. C. albicans (strain CAF2-1) was cultured in YPD at $30^{\circ} \mathrm{C}$ overnight with agitation. A HK extract was prepared with $1 \mathrm{ml}\left(\sim 4 \times 10^{8}\right.$ cells $)$ culture boiled for 45 mins. ALS1/3 peptide (KGLNDWNYPVSSESFSYT) ${ }^{33}$ was obtained from Biosynthesis (Lewisville, TX). cLN stimulation was performed by plating $10^{6}$ cells per well in the presence or absence of $2 \times 10^{6} \mathrm{HK} C$. albicans or $5-10 \mu \mathrm{g} \mathrm{ml}^{-1}$ ALS1/3 peptide (pALS) diluted in serumfree AIM V media (Invitrogen, Carlsbad, CA) with $20 \mathrm{Uml}^{-1}$ IL-2 \pm anti-CD4 Abs (BD Biosciences, San Diego, CA, clone RM4-5, $5 \mu \mathrm{g} \mathrm{ml}^{-1}$ ) or anti-MHC II (eBiosciences, San Diego, CA, clone M5/ $114.15 .2,10 \mu \mathrm{g} \mathrm{ml}^{-1}$ ). Supernatants were analyzed in duplicate for IL-17 and IFN $\gamma$ by enzyme-linked immunosorbent assay (eBiosciences).

Intracellular cytokine staining and flow cytometry. In all, $10^{6} \mathrm{cLN}$ cells per well were rested overnight at $37^{\circ} \mathrm{C}$ in serum-free AIM V media $+20 \mathrm{U} \mathrm{ml}^{-1} \mathrm{IL}-2$. Cells were stimulated with $50 \mathrm{ng} \mathrm{ml}^{-1}$ phorbol 12-myristate 13-acetate and $500 \mathrm{ng} \mathrm{ml}^{-1}$ Ionomycin (Sigma, St Louis. MO) for $4 \mathrm{~h}$ in the presence of Golgi Plug (BD Biosciences). Following stimulation, cells were stained for CD3 allophycocyanin (APC)-Cy7 (clone 145-2C11), CD4 FITC (clone GK1.5), and CD8 PerCP (clone 53-6.7). IL-17 and IFN $\gamma$ were detected with anti-IL-17$\mathrm{PE}$ and anti-IFN $\gamma$-APC. Activation markers were assessed with CD44 eFluor 450 (clone IM7) and CD27 APC (clone LG.7F9). Dead cell exclusion was performed using Live/Dead Violet Viability/Vitality Dye Kit (Invitrogen). Intracellular cytokine staining was performed with the Cytofix Cytoperm kit (BD Biosciences). Data were acquired on an LSR II and analyzed with Flowjo (Ashland, OR).

RNA extraction and real-time reverse transcriptase-PCR. Frozen tongue was homogenized in RLT lysis buffer (RNAeasy Kit, Qiagen, Valencia, CA) with a GentleMACS Dissociator (M-tubes, RNA02 program, Miltenyi). RNA was extracted with RNAeasy Kit. In all, $1 \mu \mathrm{g}$ total RNA was used to synthesize cDNA with a SuperScript III FirstStrand Synthesis System (Invitrogen). Relative quantification of indicated genes was determined by real-time PCR with SYBR Green (Quanta BioSciences, Gaithersburg, MD) normalized to GAPDH (glyceraldehyde 3-phosphate dehydrogenase). Primers were from SA Biosciences (Qiagen). Results were analyzed on a 7300 Real Time PCR System (Applied Biosystems, Carlsbad, CA).

SUPPLEMENTARY MATERIAL is linked to the online version of the paper at http://www.nature.com/mi

\section{ACKNOWLEDGEMENTS}

SLG was supported by NIH grants AR054389 and DE022550. KCM was supported by EY018355 and SK by HL105427. ACP was supported by the Medical Scientist Training Program at the University of Pittsburgh. NHS was supported by NIH Training Grant T32-CA082084. ARH was supported by Children's Hospital of Pittsburgh of UPMC and a Pediatric Infectious Disease Society Award (funded by the Stanley A Plotkin Sanofi Pasteur Fellowship Award). We thank Genentech (South San Francisco) for kindly providing IL-23 - / - mice. We thank EC Childs, A Mamo, and M Bridi for assistance. We are grateful to Dr M McGeachy, Dr LA Darville, Dr JK Kolls, Dr S Nanjappa, Dr BS Klein and Dr HR Conti for critical reading and helpful suggestions.

\section{DISCLOSURE}

SLG consults for Lycera Corporation (Plymouth, MI) and has received a research grant from Amgen and honoraria/travel reimbursements from Amgen, Novartis, and Boeringer-Ingelheim. A research grant from Novartis is currently pending.

c 2013 Society for Mucosal Immunology

\section{REFERENCES}

1. Dongari-Bagtoglou, A. \& Fidel, P. The host cytokine responses and protective immunity in oropharyngeal candidiasis. J. Dent. Res. 84, 966-977 (2005).

2. Klein, R.S., Harris, C.A., Small, C.B., Moll, B., Lesser, M. \& Friedland, G.H. Oral candidiasis in high-risk patients as the initial manifestation of the acquired immunodeficiency syndrome. N. Engl. J. Med. 311, 354-358 (1984).

3. Dong, C. Diversification of T-helper-cell lineages: finding the family root of IL-17-producing cells. Nat. Rev. Immunol. 6, 329-333 (2006).

4. Steinman, L. A brief history of $T(H) 17$, the first major revision in the $T(H) 1 /$ $\mathrm{T}(\mathrm{H}) 2$ hypothesis of T cell-mediated tissue damage. Nat. Med. 13, 139-145 (2007).

5. Farah, C., Hu, Y., Riminton, S. \& Ashman, R. Distinct roles for interleukin$12 \mathrm{p} 40$ and tumour necrosis factor in resistance to oral candidiasis defined by gene targeting. Oral Microbiol. Immunol. 21, 252-255 (2006).

6. Conti, H. et al. Th17 cells and IL-17 receptor signaling are essential for mucosal host defense against oral candidiasis. J. Exp. Med. 206, 299-311 (2009).

7. Ho, A. et al. IL-17RC is required for immune signaling via an extended SEFIR domain in the cytoplasmic tail. J. Immunol. 185, 1063-1070 (2010).

8. Lin, L. et al. Th1-Th17 cells mediate protective adaptive immunity against Staphylococcus aureus and Candida albicans infection in mice. PLoS Pathog. 5, e1000703 (2009).

9. Wuthrich, M. et al. Vaccine-induced protection against 3 systemic mycoses endemic to North America requires Th17 cells in mice. J. Clin. Invest. 121, 554-568 (2011).

10. Nanjappa, S.G., Heninger, E., Wuthrich, M., Gasper, D.J. \& Klein, B.S. Tc17 cells mediate vaccine immunity against lethal fungal pneumonia in immune deficient hosts lacking CD4(+) Tcells. PLoS Pathog. 8, e1002771 (2012).

11. Zelante, T. et al. IL-23 and the Th17 pathway promote inflammation and impair antifungal immune resistance. Eur. J. Immunol. 37, 2695-2706 (2007).

12. Acosta-Rodriguez, E.V. et al. Surface phenotype and antigenic specificity of human interleukin 17-producing Thelper memory cells. Nat. Immunol. 8, 639-646 (2007).

13. Zielinski, C.E. et al. Pathogen-induced human $\mathrm{T}(\mathrm{H}) 17$ cells produce IFN-gamma or IL-10 and are regulated by IL-1beta. Nature 484, 514-518 (2012). 
14. Huppler, A.R., Bishu, S. \& Gaffen, S.L. Mucocutaneous candidiasis: the IL17 pathway and implications for targeted immunotherapy. Arthritis Res. Ther. 14, 217 (2012).

15. Klatt, N.R. \& Brenchley, J.M. Th17 cell dynamics in HIV infection. Curr. Opin. HIV AIDS 5, 135-140 (2010).

16. Chen, Z. et al. Selective regulatory function of Socs 3 in the formation of IL17-secreting T cells. Proc. Natl. Acad. Sci. USA. 103, 8137-8142 (2006).

17. Yang, X.O. et al. STAT3 regulates cytokine-mediated generation of inflammatory helper T cells. J. Biol. Chem. 282, 9358-9363 (2007).

18. Freeman, A.F. \& Holland, S.M.. The hyper-IgE syndromes. Immunol. Allergy Clin. North Am. 28, 277-291. viii (2008).

19. Ma, C.S. et al. Deficiency of Th17 cells in hyper IgE syndrome due to mutations in STAT3. J. Exp. Med. 205, 1551-1557 (2008).

20. Milner, J.D. et al. Impaired $T(H) 17$ cell differentiation in subjects with autosomal dominant hyper-lgE syndrome. Nature 452, 773-776 (2008).

21. van de Veerdonk, F.L. et al. STAT1 mutations in autosomal dominant chronic mucocutaneous candidiasis. N. Engl. J. Med. 365, 54-61 (2011)

22. Liu, L. et al. Gain-of-function human STAT1 mutations impair IL-17 immunity and underlie chronic mucocutaneous candidiasis. J. Exp. Med. 208, 1635-1648 (2011).

23. Glocker, E.O. et al. A homozygous CARD9 mutation in a family with susceptibility to fungal infections. N. Engl. J. Med. 361, 1727-1735 (2009).

24. Plantinga, T.S. et al. Early stop polymorphism in human DECTIN-1 is associated with increased Candida colonization in hematopoietic stem cell transplant recipients. Clin. Infect. Dis. 49, 724-732 (2009).

25. Puel, A. et al. Autoantibodies against IL-17A, IL-17F, and IL-22 in patients with chronic mucocutaneous candidiasis and autoimmune polyendocrine syndrome type I. J. Exp. Med. 207, 291-297 (2010).

26. Browne, S.K. \& Holland, S.M. Immunodeficiency secondary to anticytokine autoantibodies. Curr. Opin. Allergy Clin. Immunol. 10, 534-541 (2010).

27. Kisand, K. et al. Chronic mucocutaneous candidiasis in APECED or thymoma patients correlates with autoimmunity to Th17-associated cytokines. J. Exp. Med. 207, 299-308 (2010).

28. Puel, A. et al. Chronic mucocutaneous candidiasis in humans with inborn errors of interleukin-17 immunity. Science 332, 65-68 (2011).

29. Kamai, Y., Kubota, M., Kamai, Y., Hosokawa, T., Fukuoka, T. \& Filler, S. New model of oropharyngeal candidiasis in mice. Antimicrob. Agents Chemother. 45, 3195-3197 (2001).

30. Pearson, C., Uhlig, H.H. \& Powrie, F.. Lymphoid microenvironments and innate lymphoid cells in the gut. Trends Immunol. 33, 289-296 (2012).

31. Buonocore, S. et al. Innate lymphoid cells drive interleukin-23-dependent innate intestinal pathology. Nature 464, 1371-1375 (2010).

32. Scurlock, A.M. et al. Interleukin-17 contributes to generation of Th1 immunity and neutrophil recruitment during Chlamydia muridarum genital tract infection but is not required for macrophage influx or normal resolution of infection. Infect. Immun. 79, 1349-1362 (2011).

33. Bär, E. et al. A novel Th cell epitope of Candida albicans mediates protection from fungal infection. J. Immunol. 188, 5636-5643 (2012).

34. Spellberg, B.J. et al. Efficacy of the anti-Candida rAls3p-N or rAls1p-N vaccines against disseminated and mucosal candidiasis. J Infect Dis 194, 256-260 (2006).

35. Bozza, S. et al. Dendritic cell-based vaccination against opportunistic fungi. Vaccine 22, 857-864 (2004).

36. Casadevall, A. \& Pirofski, L.A. Immunoglobulins in defense, pathogenesis, and therapy of fungal diseases. Cell Host Microbe 11, 447-456 (2012).
37. Tyznik, A.J., Sun, J.C. \& Bevan, M.J. The CD8 population in CD4-deficient mice is heavily contaminated with MHC class II-restricted T cells. J. Exp. Med. 199, 559-565 (2004).

38. Fidel, P.L. Jr. Candida-host interactions in HIV disease: implications for oropharyngeal candidiasis. Adv. Dent. Res. 23, 45-49 (2011).

39. Fenoglio, D. et al. V $\delta 1 \mathrm{~T}$ lymphocytes producing IFN- yand IL-17 are expanded in HIV-1-infected patients and respond to Candida albicans. Blood 113, 6611-6618 (2009).

40. Nigam, P., Kwa, S., Velu, V. \& Amara, R.R. Loss of IL-17-producing CD8 T cells during late chronic stage of pathogenic simian immunodeficiency virus infection. J. Immunol. 186, 745-753 (2011).

41. Lee, Y.K. et al. Late developmental plasticity in the Thelper 17 lineage. Immunity 30, 92-107 (2009).

42. Hirota, K. et al. Fate mapping of IL-17-producing T cells in inflammatory responses. Nat. Immunol. 12, 255-263 (2011).

43. Pepper, M. et al. Different routes of bacterial infection induce longlived TH1 memory cells and short-lived TH17 cells. Nat. Immunol. 11, 83-89 (2010)

44. Cua, D.J. \& Tato, C.M. Innate IL-17-producing cells: the sentinels of the immune system. Nat. Rev. Immunol. 10, 479-489 (2010).

45. Dungan, L.S. \& Mills, K.H. Caspase-1-processed IL-1 family cytokines play a vital role in driving innate IL-17. Cytokine 56, 126-132 (2011).

46. Kagami, S., Rizzo, H.L., Kurtz, S.E., Miller, L.S. \& Blauvelt, A.. IL-23 and IL17A, but not IL-12 and IL-22, are required for optimal skin host defense against Candida albicans. J. Immunol. 185, 5453-5462 (2010).

47. Quintin, J. et al. Candida albicans infection affords protection against reinfection via functional reprogramming of monocytes. Cell Host Microbe 12, 223-232 (2012).

48. Hernández-Santos, N. \& Gaffen, S.L. Th17 cells in immunity to Candida albicans. Cell Host Microbe 11, 425-435 (2012).

49. Puel, A., Picard, C., Cypowyj, S., Lilic, D., Abel, L. \& Casanova, J.L. Inborn errors of mucocutaneous immunity to Candida albicans in humans: a role for IL-17 cytokines?. Curr. Opin. Immunol. 22, 467-474 (2010).

50. Iwakura, Y., Ishigame, H., Saijo, S. \& Nakae, S. Functional specialization of interleukin-17 family members. Immunity 34, 149-162 (2011).

51. Naglik, J. \& Moyes, D. Epithelial cell innate response to Candida albicans. Adv. Dent. Res. 23, 50-55 (2011).

52. Cheng, S.C. et al. Candida albicans dampens host defense by downregulating IL-17 production. J. Immunol. 185, 2450-2457 (2010).

53. Kweon, M. Sublingual mucosa: A new vaccination route for systemic and mucosal immunity. Cytokine 54, 1-5 (2011).

54. Bik, E.M. et al. Bacterial diversity in the oral cavity of 10 healthy individuals. ISME J 4, 962-974 (2010).

55. Ivanov, I.I. et al. Specific microbiota direct the differentiation of IL-17producing T-helper cells in the mucosa of the small intestine. Cell Host Microbe 4, 337-349 (2008).

56. Zelante, T., lannitti, R., De Luca, A. \& Romani, L. IL-22 in antifungal immunity. Eur J. Immunol. 41, 270-275 (2011).

57. Pietrella, D. et al. Th17 cells and IL-17 in protective immunity to vaginal candidiasis. PLoS One 6, e22770 (2011).

58. Lilly, E.A., Yano, J. \& Fidel, P.L. Jr. Annexin-A1 identified as the oral epithelial cell anti-Candida effector moiety. Mol. Oral. Microbiol. 25, 293-304 (2010).

59. Yano, J., Lilly, E., Barousse, M. \& Fidel, P.L. Jr. Epithelial cell-derived S100 calcium-binding proteins as key mediators in the hallmark acute neutrophil response during Candida vaginitis. Infect Immun 78, 5126-5137 (2010). 